\title{
Estratégias ofensivas e defensivas eficazes no Goalball
}

\section{RESUMO}

O objetivo deste estudo foi caracterizar e descrever as variáveis ofensivas e defensivas mais frequentes e eficazes na elite masculina do goalball e, ainda, comparálas entre equipes: vencedoras vs. perdedoras; de nível superior vs. inferior. Através do método de observação sistemática e com amostra composta por 25 partidas dos Jogos Paralímpicos Rio 2016, foram analisados 4635 arremessos e 4520 defesas. Os principais achados foram que: para o ataque, existe uma maior probabilidade de marcar gol após as interrupções do jogo; para a defesa, fazer o balanço defensivo é melhor do que não o realizar, já que a probabilidade de sofrer gol é maior quando ele não ocorre. Além disso, utilizar o tronco como segmento corporal para realizar as defesas também é mais indicado, pois a probabilidade de sofrer gol é maior quando as defesas são realizadas pelas pernas ou braços.

PALAVRAS-CHAVE: Goalball; Análise de jogo; Jogos paralímpicos; Esporte coletivo

\section{João Gabriel Dal Picolo}

Mestrado em andamento - EEFERP/USP

Escola de Educação Física e Esporte de Ribeirão Preto,

São Paulo, Brasil jgdalpicolo@usp.br

ㄴ https://orcid.org/0000-0002-2485-3820

Leonardo Travitzki

Mestrado em andamento - EEFERP/USP

Escola de Educação Física e Esporte de Ribeirão Preto,

São Paulo, Brasil

leonardo.travitzki@usp.br

(ㄷ) https://orcid.org/0000-0002-9802-5008

Isabella dos Santos Alves

Doutorado em andamento - FEF/UNICAMP

Faculdade de Educação Física da Universidade Estadual de Campinas, São Paulo, Brasil santosalvesisabella@gmail.com

그 https://orcid.org/0000-0001-7983-0653

Márcio Pereira Morato

Doutor - FEF/UNICAMP

Escola de Educação Física e Esporte de Ribeirão Preto,

São Paulo, Brasil

mpmorato@usp.br

D https://orcid.org/0000-0002-9927-1841 


\title{
Effective offensives and defensives strategies in Goalball
}

\begin{abstract}
The aim of this study was to characterize and describe the most frequent and effective offensive and defensive variables in the male goalball elite and also compare them between teams: winner vs. loser; high-level vs. lower-level. Through the method of systematic observation and with a sample consisting of 25 matches of the Rio 2016 Paralympic Games, 4635 pitches and 4520 saves were recorded. The main findings were that: for the attack, there is a higher probability of scoring after game interruptions; for the defense, making the defensive balance is better than not doing it, as the probability of conceding a goal is higher when it does not occur. In addition, using the trunk as a body segment to make defenses is also more effective, as the probability of suffering a goal is higher when the defenses are performed by the legs or arms.
\end{abstract}

KEYWORDS: Goalball; Match analysis; Paralympics games; Team sport

\section{Estrategias ofensivas y defensivas efectivas en Goalball}

\section{RESUMEN}

El objetivo de este estudio fue caracterizar y describir las variables ofensivas y defensivas más frecuentes y efectivas en la élite del goalball masculino y también compararlas entre equipos: ganador vs. perdedor; nivel alto vs. nivel inferior. A través del método de observación sistemática y con una muestra compuesta por 25 partidos de los Juegos Paralímpicos río 2016, se registraron 4635 lanzamientos y 4520 salvamentos. Los principales hallazgos fueron que: para el ataque, hay una mayor probabilidad de anotar después de las interrupciones del juego; para la defensa, hacer el equilibrio defensivo es mejor que no hacerlo, ya que la probabilidad de encajar un gol es mayor cuando no se produce. Además, utilizar el tronco como segmento corporal para hacer defensas también es más efectivo, ya que la probabilidad de sufrir un gol es mayor cuando las defensas se realizan por las piernas o los brazos.

PALABRAS-CLAVE: Goalball; Análisis de partidos; Juegos paralímpicos; Deporte de equipo 


\section{INTRODUÇÃO}

O goalball é uma modalidade coletiva paralímpica desenvolvida a partir de 1946 pelo austríaco Hans Lorenzen e pelo alemão Sepp Haindell (MORATO; ALMEIDA, 2012). Uma característica muito peculiar que o diferencia dos outros esportes paralímpicos é que ele não foi concebido da adaptação de outra modalidade. O goalball é uma criação específica para pessoas com deficiência visual (AMORIM et al., 2010). Pessoas com baixa visão e cegueira são elegíveis para a prática competitiva desta modalidade (IBSA, 2021). A igualdade de participação entre os jogadores é assegurada pelo uso de bandagens e óculos específicos nos olhos.

O goalball possui um ciclo dinâmico de movimentos durante o jogo, envolvendo ações táticas ofensivas e defensivas. $\mathrm{Na}$ fase ofensiva ocorre o controle da bola, a preparação para o ataque e a efetivação do arremesso. Já na fase defensiva, o balanço defensivo, seguido da leitura da trajetória da bola e por fim, a interceptação da bola (MORATO; GOMES; ALMEIDA, 2012).

Para atuar na dimensão ofensiva, as equipes precisam realizar o controle de bola, que pode ser desempenhado de diferentes formas. No início do jogo ou no início do segundo tempo, o controle de bola é realizado após o passe efetuado pelo árbitro principal. Após esses procedimentos de início de jogo, esse princípio estará intimamente relacionado às ações de interceptação do arremesso adversário que, possivelmente, podem influenciar nas ações dos princípios ofensivos subsequentes. Com a bola controlada, a equipe passará a enfatizar o princípio de preparação que, de acordo com a eficácia do controle de bola, pode ser mais ou menos elaborado. Após a efetivação do arremesso, o balanço defensivo é estabelecido por todos os integrantes do time, com intuito de restabelecer o esquema tático e ocupar o espaço (área da defesa) de maneira racional. Neste momento, a leitura da trajetória da bola já começa a ser desenvolvida e a tentativa de localizar a origem, tipo e destino do arremesso são ajustados antes da efetivação da defesa, com a interceptação ou não, da bola arremessada pela equipe adversária (MORATO; GOMES; ALMEIDA, 2012).

Diante do ciclo dinâmico supracitado, de forma intermitente e com alta intensidade (ALVES et al., 2018), duas equipes disputam a partida de goalball, com o objetivo alcançar a vitória e, possivelmente, desfrutar do triunfo na competição. Nos Jogos Paralímpicos, por exemplo, as dez equipes que conquistaram a vaga, são divididas em dois grupos de cinco times cada. Os quatro melhores times de cada grupo avançam para a fase eliminatória que se inicia com as quartas de final, seguidas pelas semifinais e final (IPC, 2021). Sendo assim, os semifinalistas são considerados times de nível superior quando comparados aos times que saíram da competição nas fases 
anteriores, (quinta a décima colocação). Contudo, quais são as características, relacionadas aos princípios ofensivos e defensivos, que fazem com que as equipes vençam jogos e tenham mais êxito na competição?

Este estudo se justifica pela escassa produção acadêmica sobre esta temática, e os achados podem contribuir para que os profissionais da área possam melhorar o desenvolvimento da sua prática. Dessa forma, o objetivo do presente artigo é caracterizar e descrever as variáveis ofensivas (situação precedente, jogador atacante, técnica de arremesso, tipo de bola, estratégia ofensiva e tempo de posse de bola) e defensivas (esquema tático da defesa, balanço defensivo, jogador defensor e segmento corporal) na elite do goalball masculino. Ainda, de maneira específica, pretendemos comparar as variáveis ofensivas e defensivas que caracterizam vencedores e perdedores e, também, as equipes de nível superior $\left(1^{\circ}\right.$ ao $4^{\circ}$ colocado $)$ e inferior $\left(5^{\circ}\right.$ ao $10^{\circ}$ colocado).

\section{MÉTODO}

O estudo utilizou a abordagem científica de observação sistemática não participativa do contexto do jogo (ANGUERA; MENDO, 2013; THOMAS; NELSON; SILVERMANN, 2012). A amostra foi composta por todas as 28 partidas do torneio masculino de goalball dos Jogos Paralímpicos Rio 2016, sendo registrados 4635 arremessos e 4520 defesas. Três disputas foram excluídas das análises por não preservarem a igualdade numérica dos jogadores por equipe (3 vs. 3) ou pela obtenção da vantagem no placar maior que 10 gols.

As jogadas que não se encaixaram dentro do padrão normal do jogo (MORATO et al., 2017; MORATO et al., 2012), como as situações de arremessos que resultaram em penalidade, as cobranças de penalidade e os arremessos de bola de segurança (situações em que os jogadores, na tentativa de não exceder os 10 segundos regulamentares para a posse de bola e, então cometer uma penalidade, lançavam a bola para fora deliberadamente), também foram excluídas das análises. (MORATO et al., 2017).

O estudo foi aprovado pelo Comitê de Ética em Pesquisa da Faculdade de Filosofia, Ciências e Letras de Ribeirão Preto, Universidade de São Paulo (CAAE: 20768513.3.0000.5407). A International Blind Sports Federation (IBSA) concedeu a permissão para a gravação dos jogos e o Comitê Paralímpico Internacional autorizou por escrito o uso de vídeos das partidas de goalball dos Jogos Paralímpicos Rio 2016 para fins científicos. 


\section{Protocolo de análises}

Os indicadores de ação foram elaborados e estabelecidos em conjunto pelos autores M.P.M (12 anos de experiência como treinador de goalball), J.G.D.P (experiência de dois anos em análise de desempenho do goalball) e L.T (experiência de três anos em análise de desempenho do goalball). Todas as análises dos indicadores foram realizadas por dois avaliadores (J.G.D.P. e L.T.). Para a análise dos vídeos foi utilizado o software Kinovea (versão 0.8.15, Copyright (C 2006-2011) junto ao instrumento ad hoc (adaptado de MORATO et al., 2017) confeccionado para o preenchimento simultâneo em planilha eletrônica (Microsoft Excel 2013). Foram avaliadas as variáveis de ação, baseadas no estudo de Morato et al. (2017), que estão apresentados na Tabelas 1 e 2.

Além disso, foram adicionadas duas variáveis independentes: 1) nível da equipe; 2) resultado da partida. O nível das equipes foi dividido em superior e inferior, sendo as equipes superiores as equipes semifinalistas do torneio ( $1^{\mathrm{a}}$ a $4^{\mathrm{a}}$ colocação) e inferiores as demais equipes $\left(5^{\mathrm{a}}\right.$ a $10^{a}$ colocação). Já o resultado da partida foi utilizado para classificar as equipes como vencedoras e perdedoras, sendo o jogo como unidade de análise.

A confiabilidade inter-avaliadores foi verificada em $25 \%$ da amostra selecionada aleatoriamente. Enquanto a confiabilidade intra-avaliador foi realizada em duas sessões de análises, separadas por 15 dias pelo mesmo avaliador, com a mesma porcentagem da amostra selecionada para cada observador (O’DONOGHUE, 2010; THOMAS; NELSON; SILVERMANN, 2012). O índice Kappa de Cohen foi adotado para mensurar a confiabilidade intra e interobservadores (FLEISS; LEVIN; PAIK, 2003). 
Tabela 1. Descrição dos indicadores das ações ofensivas e seus respectivos valores de confiabilidade inter e intra observador segundo o índice Kappa de Cohen.

\begin{tabular}{lccc}
\hline Variáveis & \multicolumn{3}{c}{ Valor de Kappa } \\
\cline { 2 - 4 } Descrição & Inter & Intra & Intra \\
observadores & observador 1 & observador 2 \\
\hline
\end{tabular}

\section{Situação Precedente}

Dez segundos: transição regular, momentos quando a equipe possui 10 segundos completos para executar o ataque (e.g. arremesso para fora da equipe adversária);

Menos de dez segundos: transição curta, momentos quando a equipe possui menos que dez segundos para a

$0,99 \quad 0,97 \quad 0,98$
execução do ataque (e.g. defesa com rebotes para fora);

Interrupção: transição longa, momentos com interrupções oficiais (e.g. tempo técnico da equipe).

\section{Atacante}

Ala direito;

Ala esquerdo;

Central.

\section{Técnica de Arremesso}

Giro;

Frontal;

Entre pernas.

\section{Tipo de Bola}

Quicada;

Lisa;

Com efeito.

\section{Estratégia Ofensiva}

Regular: atacante arremessa a bola do mesmo setor que defendeu ou recebeu um passe com barulho;

Flutuação: jogador defende um arremesso ou recebe um passe barulhento e muda de setor antes do arremesso;

Contra-ataque: arremesso realizado com menos de

$0,91 \quad 0,91 \quad 0,97$
quatro segundos de posse de bola;

Jogada Combinada: jogadas pré-estabelecidas com movimentações conjuntas, envolvendo mais de um jogador.

\section{Tempo de Posse de Bola}

Padrão: entre 4 e 6,99 segundos;

Acelerada: entre 0 e 3.99 segundos;

Delongada: entre 7 e 10 segundos. 
Tabela 2. Descrição dos indicadores das ações defensivas e seus respectivos valores de confiabilidade inter e intra observador segundo o índice Kappa de Cohen.

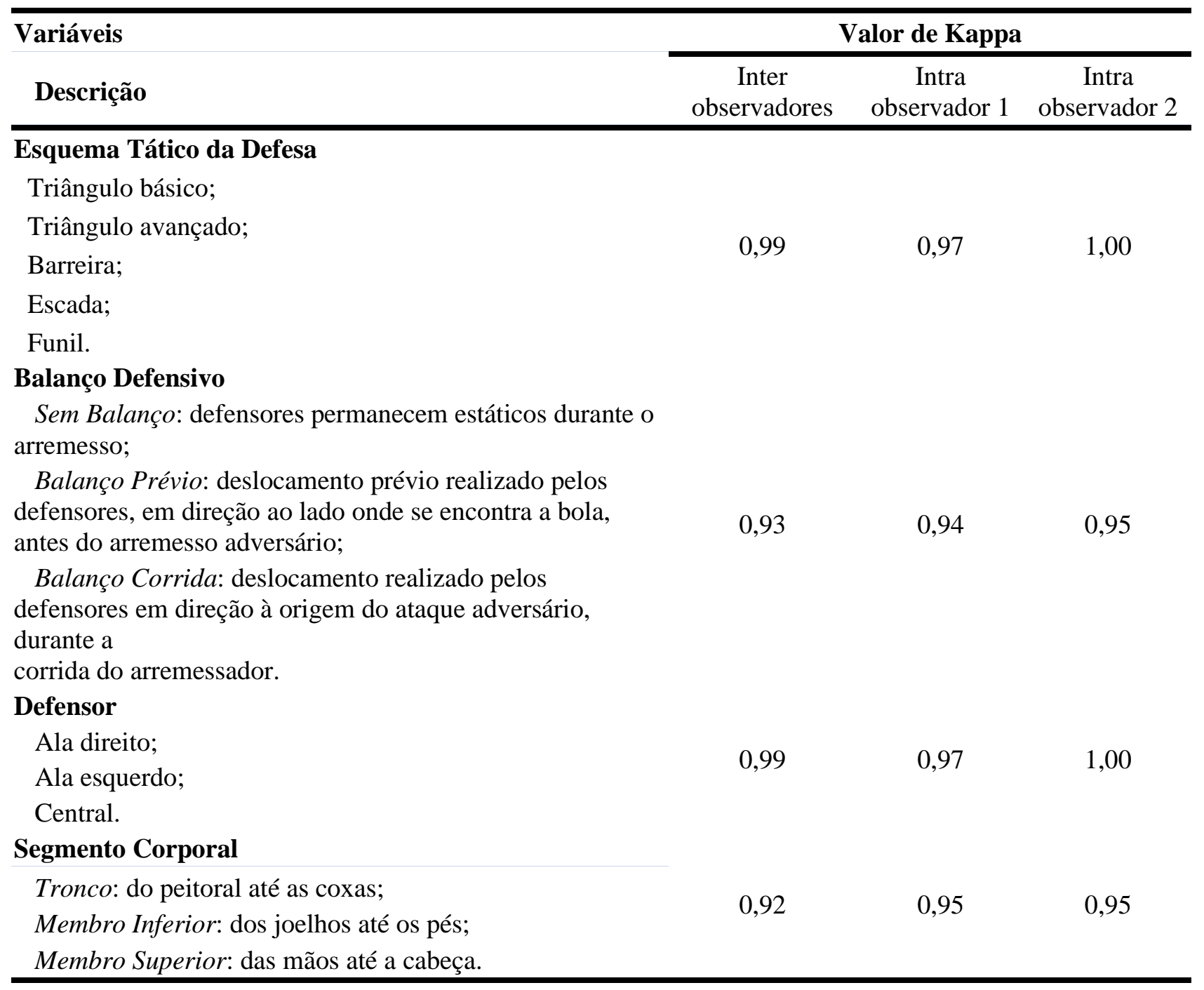

\section{Análise Estatística}

O programa IBM® SPSS para Windows (versão 20,0) foi utilizado nas análises estatísticas. A confiabilidade intra e interobservadores foi testada utilizando o índice Kappa de Cohen. Para uma primeira análise, o qui-quadrado foi utilizado para verificar se a frequência dos indicadores de performance foi igualmente distribuída e para testar quais estratégias utilizadas apresentaram maior probabilidade de marcar um gol ou para defendê-lo. Para uma segunda análise, utilizando os dados de frequência e eficácia obtidos na primeira análise, comparamos os times vencedores e perdedores utilizando o Teste-t pareado, com o jogo sendo a unidade de análise. Adicionalmente, comparamos os times superiores e inferiores, usando o Teste-t não pareado, para amostras independentes, com o time sendo a unidade de análise. O nível de significância foi fixado em $\mathrm{p}<0,05$. 


\section{RESULTADOS}

Os indicadores de ação analisados para cada variável ofensiva e defensiva demonstraram diferenças significativas na distribuição das frequências ( $p<0,001$, Tabelas 3 e 4). Dessa forma, foi possível observar uma frequência superior nas respectivas ações: 1) Ofensivas: situação precedente com duração menor que 10 segundos, desempenhada pelo ala esquerdo, com técnica de arremesso com giro, tipo de bola quicada, estratégia ofensiva regular e tempo de posse de bola padrão (Tabela 3); 2) Defensivas: esquema tático em triângulo avançado, com a utilização do balanço prévio, sendo o central o principal defensor e a utilização do tronco como segmento corporal mais frequente para interceptar o arremesso adversário (Tabela 4). É importante ressaltar que, mesmo com menor frequência, os arremessos executados após momentos de interrupção do jogo (tempo técnico, por exemplo) apresentaram, de maneira significativa, maior probabilidade de marcar um gol ( $\mathrm{p}=0,019$, Tabela 3). Em contrapartida, a não realização do balanço defensivo em direção à origem do ataque adversário ( $\mathrm{p}=0,040)$ e a utilização da perna como segmento corporal para a interceptação da bola ( $\mathrm{p}<0,001$, Tabela 4) demonstraram maior probabilidade de conceder um gol.

Ao realizar a comparação entre os times vencedores e perdedores ficou evidente a diferença de específicos indicadores de ação (Figura 1). Os times vencedores apresentaram, segundo as variáveis ofensivas, maior frequência de arremessos em situação precedente com duração menor que 10 segundos, estratégia ofensiva regular e posse de bola delongada. Ademais, arremessos realizados, pelas equipes vencedoras, em situação precedente com duração menor que 10 segundos, efetuados por um dos alas, com técnica de giro, tipo de bola quicada, por estratégia ofensiva regular e com posse de bola padrão, e apresentaram maior probabilidade para marcar gol (Figura 1A).

Os times perdedores apresentaram, segundo as variáveis ofensivas, maior frequência de arremessos em situação precedente completa de 10 segundos e com interrupção, em ataques realizados pelos jogadores centrais, estratégia ofensiva de contra-ataque e posse de bola acelerada. Em nenhuma das variáveis ofensivas, os perdedores apresentaram maior probabilidade de marcar quando comparados aos vencedores (Figura 1A). Em relação às variáveis defensivas, não houve diferenças significativas quanto à frequência. Contudo, os times perdedores apresentaram maiores chances de sofrer o gol quando realizaram o balanço prévio e quando utilizaram os braços e pernas como segmentos corporais para a defesa do ataque adversário (Figura 1B).

Por fim, ao comparar os times de nível superior (semifinalistas) e inferior (demais times), notamos que os times superiores apresentaram posse de bola delongada significativamente mais frequente (Figura 2A). Em complemento, no que se refere a probabilidade de marcar, ao efetuar 
arremessos com tipo de bola lisa e posse de bola padrão, os times superiores apresentaram, de forma significativa, maior probabilidade de marcar gol (Figura 2A). Em contraponto, os times inferiores apresentaram maior probabilidade de sofrer gol ao realizarem o balanço defensivo previamente e durante o arremesso (Figura 2B).

Tabela 3. Frequência, porcentagem de arremessos, número de gols e probabilidade de marcar gol, de acordo com as variáveis ofensivas do goalball masculino.

\begin{tabular}{|c|c|c|c|c|c|c|}
\hline \multirow{2}{*}{ Variáveis Ofensivas } & \multicolumn{3}{|c|}{$\begin{array}{c}\text { Frequência e porcentagem de } \\
\text { arremessos } \\
\end{array}$} & \multicolumn{3}{|c|}{$\begin{array}{c}\text { Número de gols e probabilidade de } \\
\text { marcar }\end{array}$} \\
\hline & $N(\%)$ & $\begin{array}{c}\text { Qui- } \\
\text { Quadrado }\end{array}$ & Valor $P$ & $N(\%)$ & $\begin{array}{c}\text { Qui- } \\
\text { Quadrado }\end{array}$ & Valor $P$ \\
\hline \multicolumn{7}{|l|}{ Situação Precedente } \\
\hline Menos de 10 segundos & $3494(75,4)$ & & & $159(4,5)$ & & \\
\hline 10 segundos & $788(17)$ & 3749,20 & $<0,001$ & $39(4,9)$ & 7,91 & 0,019 \\
\hline Interrupção & $353(7,6)$ & & & $28(7,9)$ & & \\
\hline \multicolumn{7}{|l|}{ Atacante } \\
\hline Ala esquerdo & $2042(44,1)$ & & & $96(4,7)$ & & \\
\hline Ala direito & $2026(43,7)$ & 928,71 & $<0,001$ & $95(4,6)$ & 2,34 & 0,310 \\
\hline Central & $567(12,2)$ & & & $35(6,1)$ & & \\
\hline \multicolumn{7}{|l|}{ Técnica de Arremesso } \\
\hline Giro & $3305(71,3)$ & & & $170(5,1)$ & & \\
\hline Frontal & $1278(27,6)$ & 3493,81 & $<0,001$ & $53(4,1)$ & 2,06 & 0,356 \\
\hline Entre pernas & $52(1,1)$ & & & $3(5,7)$ & & \\
\hline \multicolumn{7}{|l|}{ Tipo de Bola } \\
\hline Quicada & $4521(97,5)$ & & & $217(4,8)$ & & \\
\hline Lisa & $106(2,3)$ & 8601,73 & $<0,001$ & $8(7,5)$ & 2,69 & 0,261 \\
\hline Efeito & $8(0,2)$ & & & $1(12,5)$ & & \\
\hline \multicolumn{7}{|l|}{ Estratégia de Arremesso } \\
\hline Regular & $3331(71,9)$ & & & $150(4,5)$ & & \\
\hline Flutuação & $1090(23,5)$ & 500475 & $<0001$ & $65(5,9)$ & 386 & 0277 \\
\hline Contra-ataque & $180(3,9)$ & & 0,001 & $9(5,0)$ & & \\
\hline Jogada combinada & $34(0,7)$ & & & $2(5,8)$ & & \\
\hline \multicolumn{7}{|l|}{ Tempo de Posse de Bola } \\
\hline Padrão & $2520(54,4)$ & & & $121(4,8)$ & & \\
\hline Delongada & $1365(29,4)$ & 1045,34 & $<0,001$ & $69(5,0)$ & 0,13 & 0,935 \\
\hline Acelerada & $750(16,2)$ & & & $36(4,8)$ & & \\
\hline
\end{tabular}


Tabela 4. Frequência, porcentagem de arremessos, número de gols e probabilidade de conceder o gol, de acordo com as variáveis defensivas do goalball masculino.

\begin{tabular}{|c|c|c|c|c|c|c|}
\hline \multirow{2}{*}{ Variáveis Defensivas } & \multicolumn{3}{|c|}{$\begin{array}{l}\text { Frequência e porcentagem das } \\
\text { defesas }\end{array}$} & \multicolumn{3}{|c|}{$\begin{array}{l}\text { Número de gols e probabilidade de } \\
\text { gols sofridos }\end{array}$} \\
\hline & $N(\%)$ & $\begin{array}{c}\text { Qui- } \\
\text { Quadrado }\end{array}$ & Valor $P$ & $N(\%)$ & $\begin{array}{c}\text { Qui- } \\
\text { Quadrado }\end{array}$ & Valor $P$ \\
\hline \multicolumn{7}{|c|}{ Esquema Tático da Defesa } \\
\hline Triângulo avançado & $2304(56,8)$ & & & $128(5,6)$ & & \\
\hline Triângulo básico & $1310(32,3)$ & & & $73(5,6)$ & & \\
\hline Barreira & $311(7,7)$ & 4736,88 & $<0,001$ & $20(6,4)$ & 2,15 & 0,709 \\
\hline Escada & $104(2,6)$ & & & $5(4,8)$ & & \\
\hline Funil & $27(0,7)$ & & & $0(0,0)$ & & \\
\hline \multicolumn{7}{|l|}{ Balanço Defensivo } \\
\hline Balanço prévio & $2848(70,2)$ & & & $147(5,2)$ & & \\
\hline Balanço corrida & $692(17,1)$ & 2494,46 & $<0,001$ & $38(5,5)$ & 6,45 & 0,040 \\
\hline Sem balanço & $516(12,7)$ & & & $41(7,9)$ & & \\
\hline \multicolumn{7}{|l|}{ Defensor } \\
\hline Central & $1698(42,7)$ & & & $71(4,2)$ & & \\
\hline Ala direito & $1188(29,8)$ & 159,63 & $<0,001$ & $40(3,4)$ & 1,59 & 0,452 \\
\hline Ala esquerdo & $1093(27,5)$ & & & $38(3,5)$ & & \\
\hline \multicolumn{7}{|l|}{ Segmento Corporal } \\
\hline Tronco & $2212(55,6)$ & & & $33(1,5)$ & & \\
\hline Membros inferiores & $914(23,0)$ & 888,52 & $<0,001$ & $75(8,2)$ & 84,28 & $<0,001$ \\
\hline Membros superiores & $853(21,4)$ & & & $41(4,8)$ & & \\
\hline
\end{tabular}

Nota - Foram contabilizados 77 arremessos nos quais a bola não tocou em nenhum defensor, para a frequência representou $1,9 \%$ do total dos arremessos e para probabilidade, nesses casos, todos as bolas foram gols, sendo $100 \%$ de probabilidade de marcar. 
Figura 1. Comparação entre os times vencedores e perdedores, referente à porcentagem média de arremessos e a probabilidade média de marcar gol.

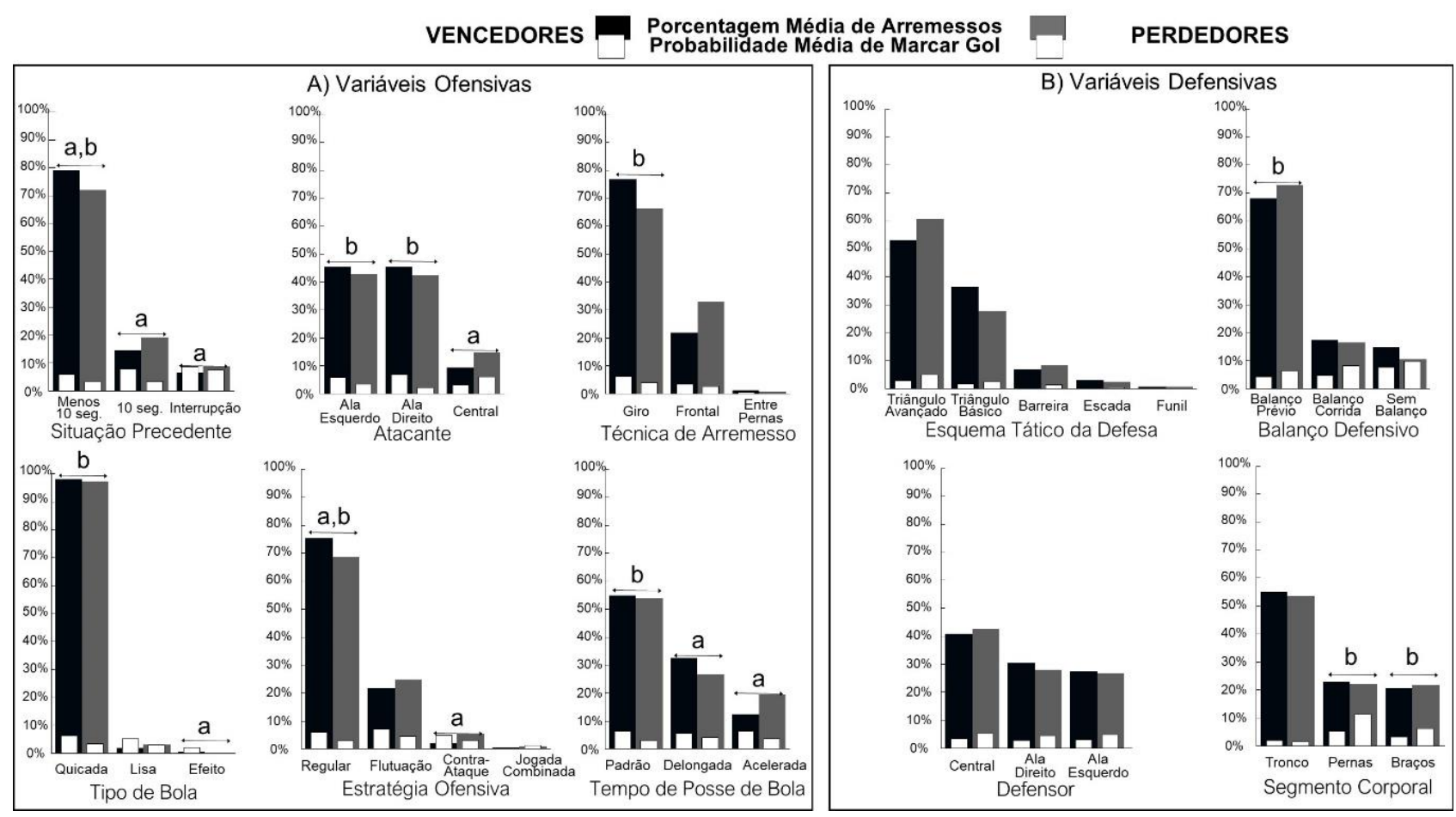

Legenda: o indicador "a" representa diferença significativa $(\mathrm{p}<0,05)$ para frequência e o indicador "b" representa diferença significativa $(\mathrm{p}<0,05)$ para probabilidade.

Figura 2. Comparação entre os times semifinalistas e demais times, referente à porcentagem média de arremessos e a probabilidade média de marcar gol.

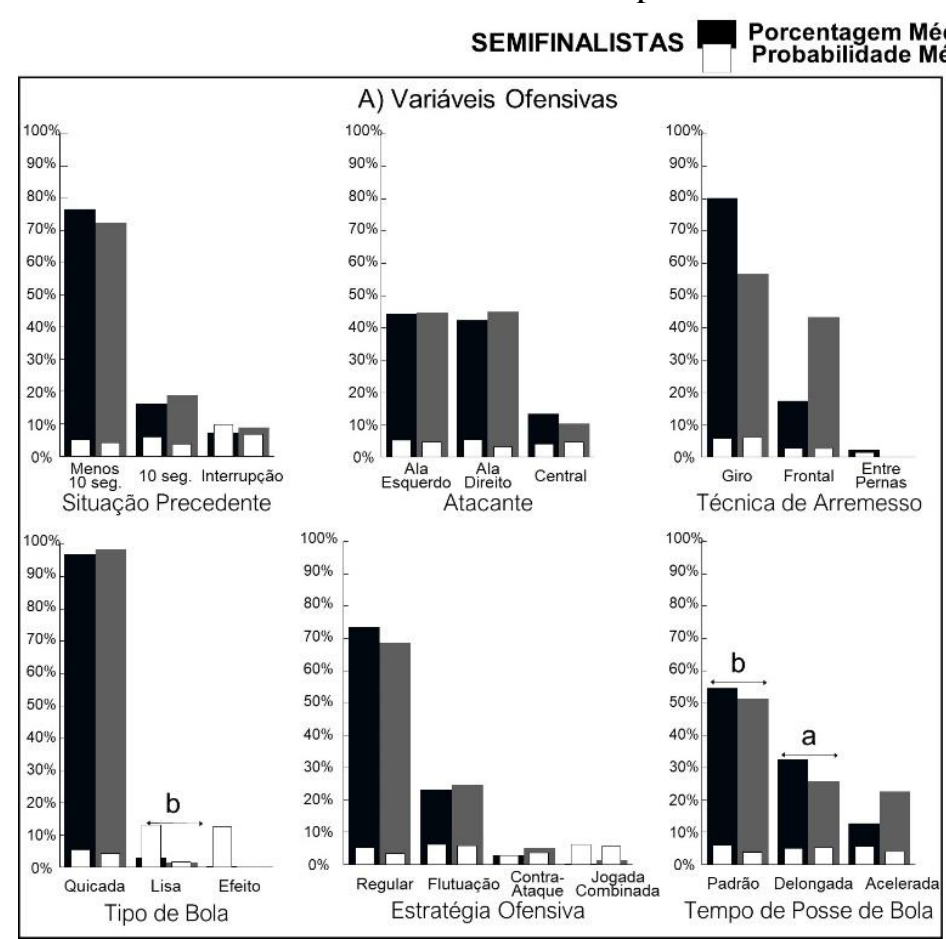

dia de Marrear Gol

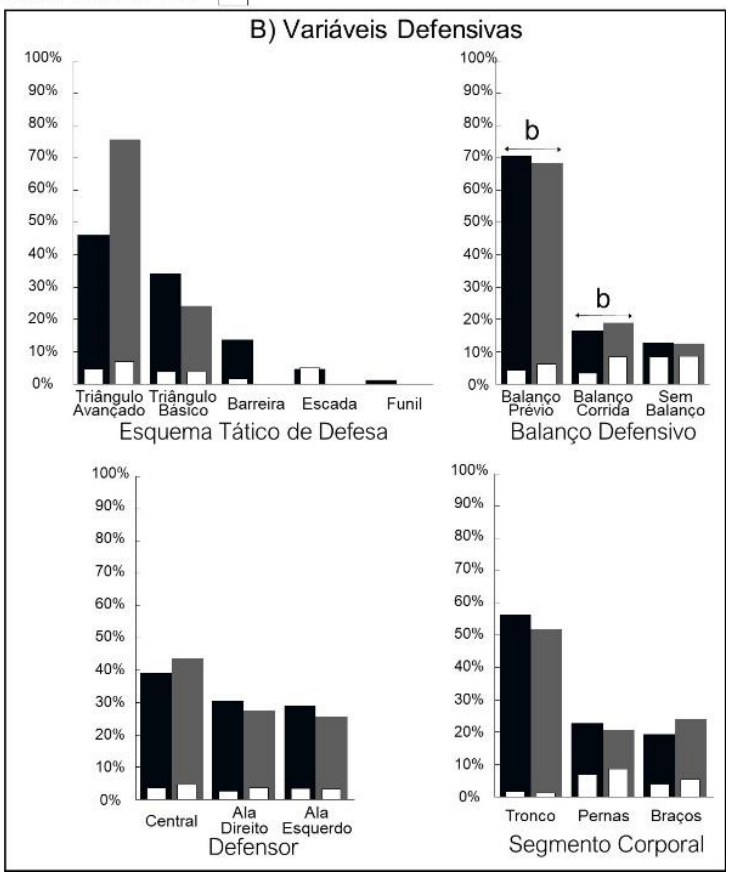

Legenda: o indicador "a" representa diferença significativa $(p<0,05)$ para frequência e o indicador "b" representa diferença significativa $(\mathrm{p}<0,05)$ para probabilidade. 


\section{DISCUSSÃO}

O objetivo do presente estudo foi caracterizar e descrever as variáveis ofensivas e defensivas mais frequentes e eficazes na elite masculina do goalball e, compará-las entre times vencedores e perdedores e, equipes de nível superior e inferior. Em 25 jogos, os indicadores de ação ofensivos e defensivos mais frequentes nem sempre se mostraram os mais eficazes para as equipes.

A situação precedente ao arremesso, composta por interrupções oficiais, bem como o uso das extremidades corporais como segmentos da defesa propiciaram maior probabilidade de realização de um gol ou de sua concessão, respectivamente, portanto merecem atenção durante a partida. Com objetivo de obter sucesso no jogo, times vencedores obtiveram maior probabilidade de gol ao realizarem, especificamente, as seguintes ações: arremessos realizados por estratégia regular, com posse de bola padrão e situação precedente com duração menor que 10 segundos, efetuados por um dos alas, com técnica de giro e tipo de bola quicada. Em complemento, para as equipes mais bem sucedidas no ranking, a utilização da posse de bola padrão também se mostrou eficaz.

Para iniciar uma discussão detalhada sobre cada indicador de ação, a situação precedente da equipe em fase ofensiva será destacada. Um aspecto importante sobre este indicador é a sua variabilidade temporal e referencial. Situações precedentes com duração menor ou igual a 10 segundos requerem a elaboração da tomada de decisão e, consequentemente, dos princípios ofensivos em função de um tempo contrarrelógio para não cometer uma penalidade (MORATO et al., 2012). Tal circunstância, ainda em situação de jogo, permite que a equipe adversária se organize defensivamente em detrimento das últimas referências sonoras da bola e dos adversários. Contudo, quando ocorrem instabilidades nesse sistema, como em situações de interrupção oficial, tempo técnico ou substituições, por exemplo, além de haver um tempo prolongado para descanso e elaboração de uma jogada da equipe ofensiva, é requerido a auto-organização da equipe defensiva sem uma referência prévia do contexto de jogo. Dessa forma, o jogador pode optar por uma caminhada silenciosa para mudar o setor de arremesso, fazer uma flutuação e, possivelmente, deturpar o balanço defensivo da equipe adversária.

Adiante a situação precedente, o posicionamento do arremessador tende a influenciar significativamente na frequência (MOLIK et al., 2015; MONEZI al., 2018; MORATO et al., 2018), velocidade da bola arremessada (MONEZI et al., 2018) e alvo alcançado na quadra adversária (FUJITA; FURTADO; MORATO, 2021). De todos os arremessos realizados nos 25 jogos, 87,8\% foram realizados por alas esquerdos $(44,1 \%)$ e direitos $(43,7 \%)$. Corroboram estes achados, outros estudos que também demonstraram maior frequência de arremessos advindos de atletas nestas posições (MOLIK et al., 2015; MONEZI al., 2018; MORATO et al., 2018), situadas em setores 
extremos da quadra (FUJITA; FURTADO; MORATO, 2021). Essa especificidade tática-técnica tem se mostrado predominante nas quadras principalmente por alguns fatores. A disposição mais recuada em quadra favorece um incremento na velocidade de aproximação pela maior distância percorrida durante a realização do arremesso (MONEZI et al., 2018). Além disso, atletas com maior acuidade e campo visual, que se situam em grande parte em posição de ala, apresentam um incremento da aprendizagem da técnica de arremesso justamente por utilizarem a visão remanescente no treinamento, que colabora para um desempenho ofensivo com maior eficácia nos jogos (MOLIK et al., 2015).

Tão importante quanto a reflexão da posição do arremessador é a técnica de arremesso escolhida. No presente estudo, a técnica com giro apresentou maior frequência de ocorrência em todos os jogos $(71,3 \%)$ e demonstrou maior probabilidade de marcar um gol quando utilizada pelos times vencedores (6,3\%). De fato, a utilização do arremesso com giro incrementa a velocidade da bola quando comparada à técnica tradicional de arremesso frontal, embora, sua utilização nem sempre seja preferida por jogadores de goalball (BOWERMAN, 2011). A execução do arremesso com giro deve ser composta por uma rotação de $360^{\circ}$ para gerar uma força centrífuga (MORATO; GOMES; ALMEIDA, 2012) e, esse processo requer um equilíbrio postural dinâmico. Tal atributo é influenciado pela restrição total ou diminuição da acuidade e campo visual em jogadores de goalball (AYDOĞ et al., 2006) o que justifica a preferência por uma técnica que necessita de menor controle postural (i.e. técnica de arremesso frontal). Contudo, é de conhecimento que o aumento do treinamento do goalball pode contribuir para o aprimoramento do equilíbrio (AKINOGLU; KOCAHAN, 2018; BEDNARCZUK et al., 2017) e, por isso, mais recentemente, técnica de arremesso com giro tem se demonstrado mais usual em atletas do goalball masculino (LINK; WEBER, 2018).

O arremessador devidamente posicionado, opta por uma técnica de arremesso e em conjunto planeja o tipo de trajetória bola. O uso bola quicada se mostrou a mais frequente entre todas as equipes $(97,5 \%)$ e mais eficaz quando realizada pelos times vencedores $(6,2 \%)$. Link e Weber (2018) corroboram com tais achados na medida que esse fundamento foi mais utilizado em 63 jogos de goalball masculino advindos das Paralimpíadas de 2012 e 2016 e dos Campeonatos Europeus de 2013 e 2015. Vale a pena destacar que um estudo realizado com as partidas de goalball dos Jogos Paralímpicos de Pequim 2008 demonstraram resultados parecidos (MORATO et al., 2018). Neste estudo, a distribuição dos tipos de bola apresentou uma semelhança com o nosso estudo, apresentando uma alta frequência de arremessos com giro. Ademais, Furtado et al. (2021), mostrou que nas penalidades ocorridas durante jogos de goalball, em competições de nível mundial, a maior parte dos arremessos é realizada com bola quicada. 
Dentre as estratégias ofensivas utilizadas pelas equipes do goalball, a estratégia regular foi a mais frequente, estratégia na qual o atacante efetua o arremesso de setor onde defendeu ou recebeu um passe (MORATO et al. 2012; 2017). Os arremessos são efetuados na maioria das vezes pelos alas, dos setores 1 e 2 (mais próximos da lateral direita) ou 5 e 6 (lateral esquerda) da quadra e direcionados para o centro (FUJITA; FURTADO; MORATO, 2021), e o central é o jogador responsável pelo maior número das defesas, o que mostra um possível padrão de jogo. Além disso, vimos que os jogadores mais técnicos arremessam bolas mais rápidas, independente do setor ou da estratégia ofensiva, e quanto mais rápido, maior a chance de marcar gol (MORATO et al., 2018). Fato que evidencia a importância do treinamento físico aliado ao treinamento técnico para jogadores da elite do goalball, para que estes possam desenvolver força e potência específica para realizar os arremessos. Contudo, também vimos que os times perdedores apresentaram maior frequência para estratégia de arremesso de contra-ataque, o que pode ser explicado por estar atrás do placar, que o arremesso foi muito rápido e dificultou a defesa, ou eles simplesmente precisar acelerar o jogo para buscar o resultado.

O tempo de posse de bola padrão (4 a 6,99 segundos) foi o mais frequente dentre as equipes. Quando comparamos os times vencedores e perdedores, os vencedores mostraram uma maior frequência para a posse de bola delongada ( 7 a 10 segundos) e os perdedores maior frequência para posse de bola acelerada ( 0 a 3,99 segundos), o que mostra uma relação entre tempo de posse de bola e estratégia ofensiva, por exemplo: os times perdedores utilizaram uma posse de bola acelerada, combinada com arremessos de contra-ataque, para acelerar o jogo e tentar reverter o placar. Já os times vencedores e os times superiores (semifinalistas), utilizaram mais a posse de bola delongada, para gastar o tempo, já que estão ganhando. Fato que também pode ser explicado pela qualidade técnica das equipes. Uma boa equipe, realiza a defesa e rapidamente coloca a bola na mão dos atacantes, para que eles possam pensar e executar o arremesso durante os 10 segundos permitidos. Já as equipes inferiores, normalmente não tem esse tempo para planejar o ataque, pois na maioria das vezes estão atrás no placar e precisam acelerar o jogo para tentar reverter o resultado. Apesar de suportadas por um raciocínio indutivo a partir de nossos achados, essas suposições ainda precisam ser verificadas em novos estudos.

Em relação aos parâmetros defensivos, o esquema tático mais frequente foi o triângulo avançado e não houve diferença significativa para frequência e probabilidade de marcar quando comparado os times vencedores e perdedores, e comparando os times superiores (semifinalistas) e inferiores (demais times).

A realização do balanço prévio foi predominante $(70,2 \%)$ entre as táticas de balanço defensivo. É interessante ressaltar que, a execução do balanço prévio pelas equipes perdedoras e 
inferiores, apresentou maior probabilidade de sofrer gol. Por ser a primeira fase do ciclo defensivo da equipe, iniciado imediatamente após a efetivação do arremesso (MORATO et al., 2012), o balanço defensivo é parte fundamental para a interceptação e necessita de boa organização coletiva dos jogadores em quadra com a finalidade de preencher os pontos mais vulneráveis. Apesar deste resultado, não realizar o balanço defensivo é ainda pior, tanto para as equipes vencedoras ou perdedoras, quanto para superiores e inferiores, já que é importante que a defesa cubra a região central da quadra, que é para onde a maioria dos arremessos são direcionados (FUJTTA; FURTADO; MORATO, 2021). E com um balanço defensivo prévio e efetivo, é possível realizar essa cobertura e ainda utilizar o tronco para defender, pois como encontramos em nosso estudo, este segmento corporal é mais eficiente em relação aos membros superiores e inferiores.

Para discutir esta probabilidade de sofrer gol das equipes perdedoras e os inferiores, é possível que os times vencedores tenham arremessos melhores, direcionando-os para as extremidades e com bolas mais rápidas (MORATO et al., 2018), dificultado a defesa, mesmo que seja realizado o balanço prévio. Pois como também vimos neste presente estudo, arremessos direcionados as extremidades (membros inferiores e superiores) do defensor, possuem maior probabilidade de marcar gol.

De todas as defesas realizadas durante os 25 jogos analisados, $47,2 \%$ foram realizadas pelos centrais. Esse achado corrobora com o estudo realizado por Molik et al. (2015) que também demonstrou maior frequência das interceptações efetuadas por parte dos centrais. Molik et al. (2015) mostra que esse especificidade defensiva tática-técnica apresenta forte relação com o nível de acuidade visual do jogador, no qual, atletas com menor acuidade visual tem mostrado predominância na posição central, assim como, melhor desempenho nas tarefas defensivas. O melhor aproveitamento durante as defesas é explicado devido à alta sensibilidade auditiva para a organização tática da defesa e, por isso, o posicionamento estratégico do central propicia uma leitura da trajetória da bola mais eficiente na fase defensiva (MOLIK et al., 2015). Além do fator da acuidade visual, quando a equipe está sincronizada, realizando o balanço defensivo de forma efetiva, uma maior parte da quadra é coberta pelo central, fato que também pode explicar este resultado.

O tronco foi o segmento corporal mais utilizado nas ações defensivas, na maioria das vezes, pelo central, jogador mais exigido no âmbito defensivo, este resultado pode estar ligado a maior área de cobertura por este atleta e pelo maior direcionamento dos arremessos para a parte central da quadra (FUJITA; FURTADO; MORATO, 2021). Quando olhamos para o segmento corporal, vimos que o tronco possui maior eficácia defensiva, diferente da perna, que apresenta ineficácia significativa. Assim, notamos as extremidades como os segmentos com maiores probabilidades de 
resultar em gol (MORATO, 2012). Isso se justifica pelo fato das extremidades (i.e. braços e pernas) serem as responsáveis por cobrir as lacunas existentes entre os jogadores e suas posições em quadra (LINK; WEBER, 2018).

\section{CONCLUSÃO}

Os principais achados deste trabalho podem ser separados para os princípios ofensivos e defensivos. Para o ataque, existe uma maior probabilidade de marcar gol após as interrupções do jogo (tempos oficiais e transições longas). Dessa forma, as equipes devem aproveitar estes momentos para utilizar estratégias de ataque elaboradas ou aumentar a concentração para direcionar os arremessos para as regiões entre os defensores adversários, procurando atingir suas extremidades corporais, pois, nestes casos, a chance de marcar é maior.

Para a defesa, fazer o balanço defensivo, seja ele prévio ou durante o arremesso adversário, é melhor do que não o realizar, já que a probabilidade de sofrer gol é maior quando ele não ocorre. Além disso, utilizar o tronco como segmento corporal para realizar as defesas também é mais indicado, pois a probabilidade de sofrer gol é maior quando as defesas são realizadas pelas pernas ou braços.

Quando comparamos os dados dos times vencedores com os times perdedores, encontramos que os vencedores apresentam um padrão que respeita a auto-organização do jogo de goalball (situação precedente menor que dez segundos, atacando com os alas, utilizando técnica de giro, bola quicada, estratégia regular e uma posse de bola padrão), mas que é feito de maneira muito eficaz (maior probabilidade de marcar).

Algumas limitações podem ser observadas no presente estudo. A análise do posicionamento do arremessador desconsiderou uma flutuação prévia ao arremesso. Portanto, o arremessador poderia estar situado como central ou ala oposto antes de arremessar e está variação não foi demarcada. Como sugestão, estudos futuros devem considerar a interação intra-equipes em situação ofensiva. Além disso, este estudo analisou 25 jogos das Paralimpíadas Rio 2016 sob a regras estabelecidas até aquele momento. Dessa forma, as recentes alterações nas regras do goalball implementadas pela International Blind Sport Association precisam ser consideradas em análises de jogos futuros. Em complemento, novos estudos devem inserir outras variáveis contextuais nas análises, como resultado momentâneo, margem de vitória e aproveitamento de pontos na competição.

Tais achados, mostram que um ciclo auto-organizacional básico, porém bem executado, pode contribuir para o sucesso das equipes. Portanto, sugere-se que as equipes treinem, de forma 
coletiva, uma boa execução do balanço defensivo e que os atletas, de forma individual, treinem para realizar ações ofensivas e defensivas básicas, mas com máxima eficiência e qualidade.

\section{REFERÊNCIAS}

AKINOĞLU, Bither; KOCAHAN, Tuğba. Comparison of muscular strength and balance in athletes with visual impairment and hearing impairment. Journal of exercise rehabilitation, [s. 1.] v. 14, n. 5, p. 765-770, 2018. Disponível em: https://www.ncbi.nlm.nih.gov/pmc/articles/PMC6222145/. Acesso em: 19 jan. 2021.

AYDOĞ, ECE. et al. Dynamic Postural Stability in Blind Athletes Using The Biodex Stability System. International Journal of Sports Medicine, [s. l.], v. 27, n. 5, p. 415-418, 2006. Disponível em: https://www.thieme-connect.com/products/ejournals/abstract/10.1055/s-2005-865777. Acesso em: 19 jan. 2021.

ALMEIDA, Carlos; VOLOSSOVITCH, Anna; DUARTE, Ricardo. Penalty kick outcomes in UEFA club competitions (2010-2015): the roles of situational, individual and performance factors. International Journal of Performance Analysis in Sport, [s. 1.], v. 16, n. 2, p. 508-522, 2016. Disponível em: https://www.tandfonline.com/doi/abs/10.1080/24748668.2016.11868905. Acesso em: 26 mar. 2021.

ALVES, Isabella Santos. et al. Relationships Between Aerobic and Anaerobic Parameters With Game Technical Performance in Elite Goalball Athletes. Frontiers in Physiology, [s. 1.] v. 9, n. 1636, p. 1-10, 2018. Disponível em: https://www.frontiersin.org/articles/10.3389/fphys.2018.01636/full. Acesso em: 15 ago. 2020 .

AMORIM, Minerva. et al. Goalball: uma modalidade desportiva de competição. Revista Portuguesa de Ciências do Desporto, [s. 1.] v. 10, n. 1, p. 221-229, 2010. Disponível em:

https://rpcd.fade.up.pt/ arquivo/artigos soltos/vol.10 nr.1/3.1.pdf. Acesso em: 15 ago. 2020.

ANGUERA, Maria Teresa; MENDO, Antonio Hernandéz. La metodología observacional en el ámbito del deporte. Revista de Ciencias del Deporte, Espanha, v.9, n.3. p.135-160, 2013. Disponível em: http://diposit.ub.edu/dspace/bitstream/2445/108477/1/629241.pdf. Acesso em: 15 ago. 2020.

BEDNARCZUK, Grzgorz. et al. Static balance of visually impaired paralympic goalball players. International Journal of Sports Science \& Coaching. [s. 1.] v. 12, n. 5, p. 611-617, 2017. Disponível em: https://journals.sagepub.com/doi/abs/10.1177/1747954117727791 ?journalCode=spoa. Acesso em: 19 jan. 2021.

BOWERMAN, Stephanie. et al. Phases of movement of goalball throw related to ball velocity. Insight: Research and Practice in Visual Impairment and Blindness, [s. 1.] v. 4, p. 153-159, 2011. Disponível em: https://www.scielo.br/j/rbce/a/gZVJdFR6VFPSBjdvyktVmsq/?lang=en. Acesso em: 18 fev. 2021. CARLING, Christopher; WILLIAMS, Andrew Mark; REILLY, Thomas. Handbook of Soccer Match Analysis: a systematic approach to improving performance. Nova York: Routledge, 2005.

FLEISS, Joseph L.; LEVIN, Bruce; PAIK, Myunghee Cho. Statistical Methods for Rates and Proportions. $2^{\text {a }}$ Ed. Nova Jersey: John Wiley \& Sons, Inc. 2003.

FUJITA, Rafael; FURTADO, Otávio; MORATO, Márcio Pereira. Ball trajectories and the probability of scoring a goal in elite male goalball throws. European Journal of Adapted Physical Activity. [s. 1.] v. 14, n. 7, p. 1-11, 2021. Disponível em: https://eujapa.upol.cz/artkey/euj-202101-0007_ball-trajectories-and-theprobability-of-scoring-a-goal-in-elite-male-goalball-throws.php. Acesso em: 10 mai. 2021. 
FURTADO, Otávio.; et al. Factors Associated with Penalty Outcome on Male Elite Goalball. Adapted physical activity quarterly: APAQ. [s. 1.] p. 1-13, 2021. Disponível em:

https://pubmed.ncbi.nlm.nih.gov/33785661/. Acesso em: 20. abr. 2021.

HUGHES, Mike; BARTLETT, Roger. The use of performance indicators in performance analysis. Journal of Sports Sciences, v. 20, n. 10, p. 739-754, 2002. Disponível em:

https://www.tandfonline.com/doi/abs/10.1080/026404102320675602. Acesso em: 26 mar. 2021.

International Blind Sports Federation. Rules and Downloads. Disponível em: https://goalball.sport/aboutgoalball/rules-and-downloads/. Acesso em: 22 jul. 2020.

International Paralympic Comittee. Results Archive Rio 2016: Goalball - Men. Disponível em: https://www.paralympic.org/rio-2016/results/goalball/men. Acesso em: 22 jul. 2020.

LAMES, Martin; MCGARRY, Tim. On the search for reliable performance indicators in game sports. International Journal of Performance Analysis in Sport, v. 7, n. 1, p. 62-79, 2007. Disponível em: https://www.tandfonline.com/doi/abs/10.1080/24748668.2007.11868388. Acesso em: 26 fev. 2021.

MONEZI, Lucas Antônio. et al. Time-motion analysis of goalball players in attacks: differences of the player positions and the throwing techniques. Sports Biomechanics, v. 18, n. 5, p. 470-481, 2018. Disponível em: https://www.tandfonline.com/doi/abs/10.1080/14763141.2018.1433871?journalCode=rspb20. Acesso em: 26 fev. 2021.

MOLIK, Bartosz. et al. Game performance evaluation in male goalball players. Journal of Human Kinects, v. 48, n. 1, p. 43-51, 2015. Disponível em: https://www.ncbi.nlm.nih.gov/pmc/articles/PMC4721622/.

Acesso em: 18 fev. 2021.

MORATO, Márcio; ALMEIDA, José Júlio Gavião de. Goalball. In: MELLO, Marco Túlio de;

WINCKLER, Ciro. Esporte Paralímpico. São Paulo: Atheneu, 2012. p. 131-140.

MORATO, Márcio Pereira. et al. Development and evaluation of an observational system for goalball match analysis. Revista Brasileira de Ciências do Esporte, v. 39, n. 4, p. 398-407, 2017. Disponível em: https://www.scielo.br/j/rbce/a/FXYryXDZtghqGjyLjk9QNsy/?lang=en. Acesso em: 22 jul. 2020. MORATO, Márcio Pereira. et al. Faster balls increase the probability of scoring a goal in female and male elite goalball. Revista Brasileira de Ciências do Esporte. v 40. n. 4, p. 427-434, 2018. Disponível em: https://www.sciencedirect.com/science/article/pii/S0101328917300082. Acesso em: 18 fev. 2021.

MORATO, Márcio Pereira; GOMES, Mariana Simões Pimentel; ALMEIDA, José Júlio Gavião de. The selforganizations processes of goalball. Revista Brasileira de Ciências do Esporte, v. 34, n. 3, p. 741-760, 2012. Disponível em: https://www.scielo.br/j/rbce/a/NQBX4yR8TNTWNBC3ZzjM79K/?format=html. Acesso em: 15 ago. 2020.

SILVA, Gilberto Pereira. et al. Tempo de reação e a eficiência do jogador de goalball na interceptação/defesa do lançamento/ataque. Revista Motricidade, v. 6, n. 4, p. 13-22, 2010. Disponível em:

https://www.revistamotricidade.com/arquivo/2010 vol6 n4/v6n4a03.pdf. Acesso em: 26 mar. 2021.

O’DONOGHUE, Peter. Research methods for sports. Canada: Routledge, 2010.

THOMAS, Jerry; NELSON, Jack; SILVERMANN, Stephen. Métodos de pesquisa em atividade física.

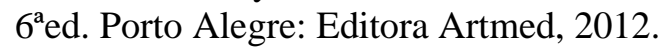




\section{NOTAS DOS AUTORES}

\section{AGRADECIMENTOS}

Nossos sinceros agradecimentos ao Laboratório de Pedagogia do Esporte, Esporte Paralímpico e Análise do Jogo (LAPEEPAJ) pelo suporto na reflexão e discussão dos resultados deste estudo e, aos membros da comissão técnica da Seleção Brasileira de Goalball Masculino e ao Comitê Paralímpico Internacional por cederem as filmagens dos jogos de goalball e permitirem a utilização, respectivamente.

CONTRIBUIÇÃO DE AUTORIA - Não se aplica.

FINANCIAMENTO - Não se aplica.

CONSENTIMENTO DE USO DE IMAGEM - Não se aplica.

APROVAÇÃO DE COMITÊ DE ÉTICA EM PESQUISA - Não se aplica.

CONFLITO DE INTERESSES - Não se aplica.

\section{LICENÇA DE USO}

Os autores cedem à Motrivivência - ISSN 2175-8042 os direitos exclusivos de primeira publicação, com o trabalho simultaneamente licenciado sob a Licença Creative Commons Attribution Non-Comercial ShareAlike (CC BY-NC SA) 4.0 International. Esta licença permite que terceiros remixem, adaptem e criem a partir do trabalho publicado, desde que para fins não comerciais, atribuindo o devido crédito de autoria e publicação inicial neste periódico desde que adotem a mesma licença, compartilhar igual. Os autores têm autorização para assumir contratos adicionais separadamente, para distribuição não exclusiva da versão do trabalho publicada neste periódico (ex.: publicar em repositório institucional, em site pessoal, publicar uma tradução, ou como capítulo de livro), com reconhecimento de autoria e publicação inicial neste periódico, desde que para fins não comerciais e compartilhar com a mesma licença.

\section{PUBLISHER}

Universidade Federal de Santa Catarina. Programa de Pós-Graduação em Educação Física. LaboMídia - Laboratório e Observatório da Mídia Esportiva. Publicado no Portal de Periódicos

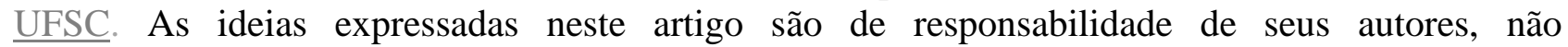
representando, necessariamente, a opinião dos editores ou da universidade.

\section{EDITORES}

Mauricio Roberto da Silva, Giovani De Lorenzi Pires, Rogério Santos Pereira.

\section{EDITOR DE SEÇÃO}

Bianca Poffo

\section{REVISÃO DO MANUSCRITO E METADADOS}

João Caetano Prates Rocha; Keli Barreto Santos, Juliana Rosário.

\section{HISTÓRICO}

Recebido em: 09 junho 2021

Aprovado em: 28 setembro 2021 